\title{
The correlation between stress and economic crisis: a systematic review
}

This article was published in the following Dove Press journal:

Neuropsychiatric Disease and Treatment

21 April 2016

Number of times this article has been viewed

\section{Nicola Mucci' \\ Gabriele Giorgi \\ Mattia Roncaioli ${ }^{3}$ \\ Javier Fiz Perez ${ }^{2}$ \\ Giulio Arcangeli'}

'Department of Experimental and Clinical Medicine, University of Florence, Florence, ${ }^{2}$ Department of Psychology, European University of Rome, Rome, ${ }^{3}$ Department of Biomedical Sciences for Health, University of Milan, Milan, Italy
Correspondence: Gabriele Giorgi European University of Rome, 190, Via degli Aldobrandeschi, I-00163 Rome, Italy

Tel +3906 66543 III

Fax +3906 66543840

Email gabriele.giorgi@unier.it
Abstract: In 2008 a deep economic crisis started in the US and rapidly spread around the world. The crisis severely affected the labor market and employees' well-being. Hence, the aim of this work is to implement a systematic review of the principal studies that analyze the impact of the economic crisis on the health of workers. We conducted our search on the PubMed database, and a total of 19 articles were selected for review. All studies showed that the economic crisis was an important stressor that had a negative impact on workers' mental health. Most of the studies documented that a rise in unemployment, increased workload, staff reduction, and wages reduction were linked to an increased rate of mood disorders, anxiety, depression, dysthymia, and suicide. Some studies showed that problems related to the crisis may have also affected the general health of workers by increasing the risk of such health problems as cardiovascular and respiratory diseases. Finally, some studies looked at the impact of the crisis on health care services. These studies demonstrated that the reduction in public expenditure on health care services, and the reduction of public hospital budgets due to the recession, led to organizational problems (eg, medical supply shortages).

Keywords: economic crisis, recession, work-related stress, mental health, risks assessment, occupational medicine

\section{Introduction}

In 2007-2008 with the bankruptcy of Lehmann Brothers Inc., a deep financial crisis began in the US. ${ }^{1}$ It soon spread to Europe and all over the world and affected all the major economies worldwide. The financial and economic crisis, called "The Great Recession", continues in many countries today (although the peak was reached in 2009) and has been considered as the most severe recession in the history of US (after "The Great Depression"). ${ }^{2}$ The crisis brought very fast growth in unemployment and it is foreseeable that it will be long lasting and that recovery will be very slow. Hence, such economic change obviously had a significant impact on workers worldwide.

Since 2007-2008, there was an increase in the unemployment rate in European countries. ${ }^{3}$ Young people were particularly affected by the crisis, indicated by the greatest youth (people $<25$ years) unemployment rate which increased in all countries from 2007 to 2009 , except Germany. ${ }^{4}$

This particular economic situation also had a wider impact on workers worldwide. The crisis of the companies, with the staff cuts and the increase in the number of unemployed people, also resulted in significant changes in the work organization for those who remained in their job positions. The crisis increased job insecurity, in particular, for those who remained employed in industries where many layoffs had already occurred. ${ }^{5}$ In addition, the reduction in staff also led to stressful workplace conditions such as an increased workload with longer shifts and less rest, reduction 
of wages, and job dissatisfaction. ${ }^{6}$ Empirical studies in Italy demonstrated that economic recession and its effects were linked to increased work-related stress, and in some cases, to the development of mental illness. ${ }^{7-12}$ This was confirmed by an influential study conducted by Houdmont et al on the employees of the Northern Ireland Civil Service. ${ }^{13}$

Considering the magnitude of "The Great Recession", in the present paper, we aimed to evaluate the impact of the economic crisis on work-related stress and mental health of workers by implementing a literature review. A systematic literature review allowed selection of the principal studies that investigated the link between the economic crisis that began in 2007-2008, and the potential effects on people's health, with particular attention to the working population.

\section{Materials and methods}

A systematic review was conducted in order to detect current scientific literature referring to the correlation between the economic crisis, work-related stress, and the health of the population. To perform our review, we chose to follow the MOOSE (Meta-analyses Of Observational Studies in Epidemiology) guidelines for meta-analyses and systematic reviews of observational studies written by the MOOSE group. ${ }^{14}$

The literature search was conducted using the PubMed platform.

The search was conducted using combinations of the following keywords in the title/abstract of papers: "economic crisis", "financial crisis", "work-related stress", "stress", and "health". The search carried out with these keywords resulted in $\sim 5,000$ citations (ie, 4,848 articles), out of which only the relevant studies were selected for the review. After the review for potential relevance, 3,733 studies were excluded because they were not specifically related to the topic of the work. Those papers, the title or abstract of which did not contain the keywords or the content of which did not explicitly refer to the correlation between economic crisis and work-related stress/health, were excluded from further review.

In addition, all articles with a publication date prior to 2010 were also excluded. This exclusion criterion was chosen due to the fact that the year 2008 has been repeatedly referred to as the year of the beginning of the crisis (although some authors report the first signs of recession in 2007)..$^{2,15-18}$ This decision led to the exclusion of an additional 745 citations. In order to make the outcomes of our systematic review as comparable and accurate as possible, we chose to include only original articles, published in English, with their full text available online to the reader. Hence, studies written in the original language of the authors, publication type different from original articles (eg, review, commentary, or correspondence), and publications with the full text not available online were excluded from the review. These criteria led to the exclusion of an additional 728 citations. The reference lists of all the included studies were examined to identify any additional studies that would meet the inclusion criteria. Following these criteria, a total of 19 articles from countries representing all continents except Africa, were included in the present review. The studies came from countries severely affected by the crisis (eg, Spain, Greece, Italy) and countries where the recession had been less felt (eg, Germany, Australia). The search was last updated in May 2015.

It is important to note that studies may range from satisfactorily meeting the quality criteria, to having some deficiencies, to not meeting the criteria at all. They can be assigned to one of the three quality categories as shown in Table 1.

The comparison of the studies would be more accurate if the studies were longitudinal rather than cross-sectional. A longitudinal study allows for assessment of the change in the prevalence of pathological aspects, considering the variation of economic and social conditions following a cohort of workers over the time.

In addition, the effects of the economic crisis would be more accurately assessed if the study used objective parameters rather than self-perceived symptoms. Studies using self-perceived symptoms collected with questionnaires have the disadvantage of being subjective. ${ }^{19}$

Finally, the effects of the crisis would be more accurately assessed if the data in the studies was collected many times over the years. ${ }^{20}$ In fact, studies presenting a longer follow-up of the outcomes allow a better assessment of the change in the health state of the population over time. ${ }^{20}$ A study in which the data were collected many times over the years

Table I Description of the quality criteria used to assess the quality of the studies

\begin{tabular}{llll}
\hline Quality categories & High quality & Moderate quality & Low quality \\
\hline Type of study & Longitudinal & Longitudinal & Cross-sectional \\
Type of parameters used & Only objective parameters & Objective parameters with standard & Only self-perceived symptoms or \\
& with standard definition & definition and self-perceived symptoms & no parameter assessed \\
Type of data collection & Data collected three or more times & Data collected just one time before & Data collected in a single interview or \\
& over the period taken into account & 2008 and one time after 2008 & questionnaire or not collected at all \\
\hline
\end{tabular}


could explain the effect of the economic recession on the health parameters better than a study in which the data were collected just once.

None of the studies examined in our review met all the quality criteria; hence, none were classified in the highquality category. The main reason for that is, there is a lack of longitudinal studies investigating the effects of economic crisis on work-related stress and health. However, 13 studies were attributed to the moderate quality group and ten publications to the low quality group (Table 1).

The results of the selected studies provided information about the crisis' effects on the workers' health and the impact on the health care services and policies. The summary of the results is provided in Table 2 .

\section{Results}

Using the procedure described in the previous section, we selected 19 articles for the current review. Of these 19 articles, ${ }^{5,6,21-37} 14$ came from European countries $^{22-24,27-29,31,32,34-38}$ (eg, Germany, ${ }^{35}$ Greece, ${ }^{6,31,38}$ Spain, ${ }^{23,27,36}$ Italy, ${ }^{32}$ Slovenia, ${ }^{24} \mathrm{UK},{ }^{34}$ Holland ${ }^{28}$ Iceland, ${ }^{29,37}$ several countries $^{22}$ ), two from the Americas ${ }^{21,33}\left(\mathrm{USA}^{33}\right.$ and Canada $\left.{ }^{21}\right)$, one from Oceania ${ }^{25}$ (Australia), two from $\mathrm{Asia}^{5,26}$ (Hong Kong and South $\mathrm{Korea}^{26}$ ), and the other two are papers published by a team of authors coming from different countries. ${ }^{22,30}$ Of the 19 articles, 12 investigated the link between the current economic crisis and aspects concerning mental health ${ }^{5,21-31}$ (such as selfperceived poor mental health, depression, anxiety, suicide), four were concerned with the correlation between crisis and aspects of general health ${ }^{32-35}$ (eg, cardiovascular, pulmonary disease, diabetes), and one aimed at explaining how the crisis has led to policy changes concerning the health system of different countries and how these changes may have affected the population's health. ${ }^{6}$ The last two articles involved work environment aspects (such as absenteeism and injuries) and their correlation with the economic crisis. ${ }^{36,37}$

\section{Economic crisis and mental health}

The greatest number of papers analyzed in the present review were concerned with the relationship between economic crisis and mental health.

Wang et $\mathrm{al}^{21}$ were aiming to estimate and compare the prevalence of mood and anxiety disorders among the workers of Alberta (Canada) during the period of economic crisis. In addition, the researchers seek to examine the demographic and socioeconomic factors associated with the mental disorders. Three thousand five hundred and seventy-nine workers were contacted by telephone at different times between January 2008 and October 2009.
The results of the study demonstrated that the prevalence rate of the major depressive disorder (MDD) significantly increased during the crisis (from 5.1\% in 2008 to $7.6 \%$ in 2009). An increase was also identified in the prevalence rate of dysthymia (from $0.4 \%$ to $1.5 \%$ ). The authors suggested that the two disorders may be related: ie, that an increased rate of depressive episodes can contribute to the development of dysthymia. Wang et $\mathrm{al}^{21}$ explained that the mental health outcomes may be due to the work-related stress linked to increased layoffs in Canada that started since 2008. The authors argued that this situation could lead workers to feel less secure about their job and experience a greater fear of salary reduction. In the study by Tennant, ${ }^{39}$ work stress and job insecurity have been, indeed, associated with the risk of major depression.

Finally, Wang et $\mathrm{al}^{21}$ demonstrated that the increase in MDD and dysthymia was especially prevalent among married workers or workers in a common-law relationship. This was explained by the greater responsibilities that these individuals face toward their family members and the greater stress that they consequently perceive. ${ }^{21}$

Evans-Lacko et $\mathrm{al}^{22}$ concentrated on the impact of the crisis on losing one's job among those working individuals who already had mental health problems at the onset of the crisis. More than 20,000 people in 27 different European countries were interviewed in 2006 and 2010. The results showed that there was an increase in the unemployment rate over time among individuals with mental health problems (the unemployment rate changed from 13.7\% in 2006 to $21.7 \%$ in 2010 ). The unemployment percentage among workers with mental health problems was greater for individuals of younger age (between 18 and 29 years old) and in those countries where a high proportion of the population believed that people with mental health problems are socially dangerous. ${ }^{22}$

The study of Gili et $\mathrm{al}^{23}$ focused on the impact of the current economic crisis in Spain. The aim of the study was to evaluate whether the current economic crisis had an effect on people's mental health problems. The study was conducted between 2006 and 2010, implementing interviews with patients entering primary care centers. The study findings demonstrated an increase in mood disorders in 2010 compared to 2006. The change was most expressed for MDD, the rate of which increased from $28.9 \%$ to $47.5 \%$; and dysthymia, the rate of which changed from $14.6 \%$ to $25.1 \%$. The increase in the prevalence rates in 2010 was also noticeable for anxiety disorders (19.7\% compared to $11.7 \%$ in 2006), somatoform disorders (from $14.8 \%$ to $21.4 \%$ ), panic attacks (from $9.7 \%$ to $15.7 \%$ ), and alcohol dependence $(0.2 \%$ and 
Table 2 Summary of the studies included in the review

\begin{tabular}{|c|c|c|c|}
\hline Authors & Year & Journal & Results \\
\hline Loerbroks et $\mathrm{a}^{35}$ & 2014 & $\begin{array}{l}\text { J Epidemiol } \\
\text { Community } \\
\text { Health }\end{array}$ & $\begin{array}{l}\text { Perceived job insecurity could be related to the new onset of asthma } \\
\text { The new incidents of asthma were linked to economic crisis }\end{array}$ \\
\hline Chang et $\mathrm{a}^{30}$ & 2013 & $B M J$ & $\begin{array}{l}\text { Time trend analysis of suicides in } 54 \text { countries. There was an excess of suicides in } 2009 \text { compared to } \\
\text { the 2000-2007 trend. The highest increase in the number of suicides was in men in the 15-24 years } \\
\text { age group (European countries) and in the } 45-64 \text { years age group (American countries). There } \\
\text { seems to be an association between the increase in suicides and the magnitude of unemployment } \\
\text { The excess of suicides was linked to the economic crisis }\end{array}$ \\
\hline Gili et $\mathrm{al}^{23}$ & 2012 & $\begin{array}{l}\text { Eur J Public } \\
\text { Health }\end{array}$ & $\begin{array}{l}\text { Compared with the pre-crisis period, the } 2010 \text { survey demonstrated an increase in mood disorders } \\
\text { (especially MDD), dysthymia, anxiety disorders, somatoform disorders, panic attacks, dependence, } \\
\text { and occasional abuse of alcohol but not in eating disorders } \\
\text { The increase in psychiatric morbidity was linked to economic crisis }\end{array}$ \\
\hline Mattei et $\mathrm{al}^{32}$ & 2014 & $\begin{array}{l}\text { Soc Psychiatry } \\
\text { Psychiatr } \\
\text { Epidemiol }\end{array}$ & $\begin{array}{l}\text { The mortality due to cardiovascular disease increased with the increased unemployment rate } \\
\text { in } 20 \text { I0. Alcohol consumption increased in } 2009 \text {. Male attempted and completed suicides were } \\
\text { attributed to unemployment and GDP } \\
\text { Mortality due to cardiovascular disease, alcohol consumption, and male suicide directly linked to } \\
\text { the economic crisis }\end{array}$ \\
\hline Avcin et $\mathrm{a}^{24}$ & 2011 & $\begin{array}{l}\text { Psychiatr } \\
\text { Danub }\end{array}$ & $\begin{array}{l}\text { Depression and anxiety increased among employees, who were affected by economic crisis. The } \\
\text { private sector was mostly affected by the crisis. Workers at risk for income insecurity and poverty, } \\
\text { those with lower income and/or bank loans, and those whose companies experienced reduced } \\
\text { profits were at increased risk for depression and anxiety symptoms } \\
\text { The increase in psychiatric morbidity was due to economic crisis }\end{array}$ \\
\hline $\begin{array}{l}\text { Astell-Burt and } \\
\text { Feng }^{34}\end{array}$ & 2013 & PLoS One & $\begin{array}{l}\text { Increase in poor health status (cardiovascular disease, respiratory health problems) was linked to } \\
\text { an increase in unemployment. Mental illness and depression were not linked to unemployment rate } \\
\text { The increased rates of cardiovascular disease and respiratory health problems were linked to } \\
\text { economic crisis }\end{array}$ \\
\hline $\begin{array}{l}\text { Modrek and } \\
\text { Cullen }^{33}\end{array}$ & 2013 & Soc Sci Med & $\begin{array}{l}\text { Layoffs and downsizing were linked to increased risk of developing hypertension and diabetes } \\
\text { (among salaried workers at the plants with the highest level of layoffs). No significant links between } \\
\text { working at a high layoff plant and developing COPD, asthma, or a new diagnosis of depression } \\
\text { Hypertension was directly linked to the recession }\end{array}$ \\
\hline Wang et $\mathrm{a}^{21}$ & 2010 & $\begin{array}{l}\text { Can Child } \\
\text { Adolesc } \\
\text { Psychiatr Rev }\end{array}$ & $\begin{array}{l}\text { Prevalence of MDD and dysthymia increased with the start of the economic crisis. This was more } \\
\text { pronounced among male workers who were married or in a common-law relationship } \\
\text { Could not be assessed whether the increase in depression was due to economic crisis or } \\
\text { exacerbation of preexisting psychopathology }\end{array}$ \\
\hline Sargent-Cox et $\mathrm{al}^{25}$ & 2011 & Soc Sci Med & $\begin{array}{l}\text { Economic slowdown was linked to the increase in the prevalence of depression and anxiety among older } \\
\text { adults. The rise in the prevalence of mental health problems was lower in the period of maximum crisis } \\
\text { The increase in psychiatric morbidity was due to economic crisis }\end{array}$ \\
\hline Lee et $\mathrm{al}^{5}$ & 2010 & $\begin{array}{l}J \text { Affect } \\
\text { Disord }\end{array}$ & $\begin{array}{l}\text { Increase in the prevalence of MDD among males and females. Higher increase in the prevalence } \\
\text { especially among people between } 55 \text { and } 65 \text { years of age, those having secondary education level, } \\
\text { among married/cohabited, divorced/widowed, employed, in the lowest and high-middle income } \\
\text { groups, and those with large investment loss } \\
\text { The increase in psychiatric morbidity was due to economic crisis }\end{array}$ \\
\hline Evans-Lacko et $\mathrm{al}^{22}$ & 2013 & PLoS One & $\begin{array}{l}\text { During the recession, the unemployment rate among the working population with mental health } \\
\text { problems increased significantly in comparison with people without mental health problems }\end{array}$ \\
\hline Rachiotis et $\mathrm{al}^{6}$ & 2014 & Int J Med Sci & $\begin{array}{l}\text { Medical supply shortages were linked with emotional exhaustion and depersonalization. Prevalence } \\
\text { of emotional exhaustion, depersonalization, and low personal accomplishment was } 44.5,43.2 \text {, } \\
\text { and } 5 \text { I.5\%, respectively. The risk factors were: type of hospital (OR: } 3.88 \text { in tertiary/universitary } \\
\text { hospital), type of work (OR: } 3.53 \text { for nursing personnel and physicians), medical supply shortages } \\
\text { (OR: } 2.92 \text { ), and absence of satisfactory rest after night shifts (OR: } 1.82 \text { ) } \\
\text { It could not be assessed if the increase in burnout was directly due to economic crisis or to an } \\
\text { exacerbation of pre-existing psychopathologies }\end{array}$ \\
\hline Miret et $\mathrm{a}^{27}$ & 2014 & $\begin{array}{l}J \text { Affect } \\
\text { Disord }\end{array}$ & $\begin{array}{l}\text { The prevalence of suicide attempts and ideation has not increased significantly in } 20 \mathrm{I} I-2012 \\
\text { compared to } 200 \mathrm{I}-2002\end{array}$ \\
\hline $\begin{array}{l}\text { Sigursteinsdòttir } \\
\text { and Rafnsdottir }{ }^{37}\end{array}$ & 2015 & Soc Sci Med & $\begin{array}{l}\text { The proportion of employees who had never been absent due to sickness dropped. There was an } \\
\text { increase in the number of days employees remained off work due to sickness. The proportion of } \\
\text { those who had gone to work while sick was higher at downsized workplaces } \\
\text { The increase in sickness was due to economic crisis }\end{array}$ \\
\hline
\end{tabular}


Table 2 (Continued)

\begin{tabular}{|c|c|c|c|}
\hline Authors & Year & Journal & Results \\
\hline Snorradottir et $\mathrm{al}^{29}$ & 2013 & Am J Ind Med & $\begin{array}{l}\text { Being directly involved in organizational and structural change was associated with the development } \\
\text { of psychological distress. Both restructuring and environment factors were associated with } \\
\text { psychological distress. The negative effects of psychological distress could be partly attenuated by } \\
\text { empowering leadership } \\
\text { The increase in psychiatric morbidity was due to the economic crisis }\end{array}$ \\
\hline ten Have et $\mathrm{al}^{28}$ & 2015 & $\begin{array}{l}\text { Soc Psychiatry } \\
\text { Psychiatr } \\
\text { Epidemiol }\end{array}$ & $\begin{array}{l}\text { Low job security increased the chance of mental disorders } \\
\text { It could not be assessed if the increase in mental disorders was directly due to economic crisis }\end{array}$ \\
\hline $\begin{array}{l}\text { Sedano de la } \\
\text { Fuente et } \mathrm{al}^{36}\end{array}$ & 2014 & J Safety Res & $\begin{array}{l}\text { From 2007, unemployment rate started to grow, while the number of workplace injuries and } \\
\text { injury rate started to reduce. The sectors with greatest decrease in workplace accidents were the } \\
\text { construction and industrial sectors. There was a rise in the average age of injured workers, a rise } \\
\text { of injured workers with more work experience, and a greater decrease in injuries of workers with } \\
\text { temporary contracts } \\
\text { The reduced rate of occupational accidents was due to economic crisis ("natural selection" in the } \\
\text { labor market) }\end{array}$ \\
\hline Chan et $\mathrm{al}^{26}$ & 2014 & $\begin{array}{l}\text { J Epidemiol } \\
\text { Community } \\
\text { Health }\end{array}$ & $\begin{array}{l}\text { Increase in the suicides during the recession period was relatively higher in unemployed than in } \\
\text { employed people. Marked increase in the number of suicides was observed among managers and } \\
\text { senior officials } \\
\text { The increase in suicide rate was due to economic crisis }\end{array}$ \\
\hline Drydakis $^{3 !}$ & 2015 & Soc Sci Med & $\begin{array}{l}\text { The increase in unemployment resulted in a deterioration of self-reported health and mental health } \\
\text { of working population in Greece (especially women) } \\
\text { The increase in psychiatric morbidity was due to economic crisis }\end{array}$ \\
\hline
\end{tabular}

Abbreviations: MDD, major depressive disorder; GDP, gross domestic product; COPD, chronic obstructive pulmonary disease; OR, odds ratio.

$2.7 \%){ }^{15}$ The models adjusted for the educational level and unemployment showed that the greatest risk for developing MDD is unemployment. Mental health challenges are more prevalent among those with mortgage payment difficulties and family members of unemployed people.

Avcin et $\mathrm{al}^{24}$ evaluated the association between economic crisis, anxiety, and depressive disorders in a total of 1,592 Slovenian workers employed in the private and public sector. The findings demonstrated that the private sector was hit hardest by the financial crisis. Workers in the private sector, and in particular those who had bank loans, who had low income, and who saw their company's profits decreasing, were at increased risk of developing depressive and anxiety symptoms. With regard to the public sector, employees complained that, due to economic crisis, the rise in workload and mobbing situations were problematic. In addition, individuals in the public sector working in education and government offices were mostly affected. ${ }^{24}$

Sargent-Cox et $\mathrm{al}^{25}$ investigated the link between economic crisis, self-reported health, and psychological functioning in a population of older Australian adults. The researchers implemented a longitudinal study with the first data collection in 2005-2006 (before the crisis) and the second measure in 2009-2010 (during the crisis). Although, Australia is considered to be one of the countries less affected by the recession, ${ }^{40,41}$ similar to the previously discussed studies (eg, Wang et al, ${ }^{21}$ Gili et al, ${ }^{23}$ and Avcin et $\mathrm{al}^{24}$ ), Sargent-Cox et $\mathrm{al}^{25}$ detected an increase in the prevalence of depression and anxiety. The rise in the prevalence of mental health problems was lower in the period of maximum crisis (April-September 2009) compared to the period that followed immediately after it (with the slight recovery in economy). The authors explained this interesting finding using a theory of "social norm" whereby it says that it is easier to accept being unemployed or having financial problems at a time when many people in the society are facing the same challenges. $^{25}$

Lee et $\mathrm{al}^{5}$ aimed to identify the impact of the economic crisis on mental disorders. The symptoms of MDD were measured following DSM IV guidelines. The authors considered this type of MDD evaluation as more sensitive to describe the impact of the crisis in comparison to the number of suicides used in many studies within the literature. The study was conducted on the general population in January-February 2007 and April-May 2009. The prevalence of MDD was higher in 2009 than in 2007. The models adjusted for age showed an increased prevalence of MDD among people aged $25-35$ years (from $9.9 \%$ to $14.3 \%$ ), 35-45 years (from $7.4 \%$ to $12.3 \%$ ), and especially between 55 and 65 years (from $4.3 \%$ to $11.6 \%$ ). ${ }^{20}$ The latter fact is explained by the greater challenges for the last age group in finding a new job after losing the current one. Regarding the family status, the 
prevalence of MDD was more increased among divorced/ widowed individuals (from $14.2 \%$ to $36 \%$ ). The prevalence of MDD was also increased among those who remained employed (from $7.4 \%$ to $11 \%$ ). ${ }^{5}$ The authors explained this with the hypothesis that this could be due to the fear of losing their jobs, reduction of wages, and/or an increase in work shifts. $^{5}$

In the models adjusted for the income per year, the authors noted a significant increase in the prevalence of MDD not only among workers with low income (<US\$10,000 per year) but also in those with medium-to-high income (between US\$30,000 and US\$60,000 per year) (MDD for this group shifted from $6.4 \%$ in 2007 to $14.7 \%$ in 2009). Finally, the prevalence of MDD was increased among those who had large investment loss compared to those who had small loss or none.

Chan et $\mathrm{al}^{26}$ investigated the correlation between suicide rate in South Korea and economic crisis. The results demonstrated an increase in the suicides during the period of recession (from January 2009 to December 2010). During the crisis, there had been a marked increase in the relative risk (RR) of suicides among managers and senior officials (RR: 0.75 before the crisis; RR: 2.81 during the period of recession). The $\mathrm{RR}$ of suicides among professionals remained unchanged (RR: 0.77 before the crisis; RR: 0.81 during the recession).

A study by Miret et al, ${ }^{27}$ conducted among respondents in Spain, aimed to investigate the link between suicidal ideation/suicide attempts with the economic crisis. The data were analyzed by comparing the data collected in 2001-2002 (before the crisis) and 2011-2012 (after the crisis). Of the 4,583 individuals interviewed in 2011-2012, 55 attempted suicide. ${ }^{27}$ Unlike the Chan et $\mathrm{al}^{26}$ study, the results showed that the prevalence of suicide attempts and ideation had not increased significantly in 2011-2012 compared to 2001-2002 (ie, the changes were from $4.35 \%$ to $3.67 \%$ regarding suicide ideation, and from $1.48 \%$ to $1.46 \%$ regarding attempted suicides). Among people of age between 18 and 49 years, a significantly higher prevalence of suicide attempts was found for those not married or in a partnership. In the 50-64 years age group, the highest prevalence was found for those who were retired or could not work due to their health status. ${ }^{27}$

In the study by ten Have et al, ${ }^{28}$ adverse psychosocial job conditions (during a time of economic crisis) were linked to workers' mental health. Low decision latitude, high psychological job demand, low job security, and low coworker support were all linked to mental health symptoms, and mental, mood, and anxiety disorders. The strongest association was found between low job security and symptoms of mental health and mental disorders (ie, RR: 1.98 for mental health symptoms; RR: 2.20 for any mental disorder; RR: 1.85 for mood disorder; RR: 2.26 for anxiety disorder; RR: 2.07 for substance use disorder). The combination of more than one adverse psychosocial working condition led to a considerable increased risk of developing mental health symptoms (RR: 4.85), any mental disorder (RR: 3.83), mood disorder (RR: 3.13), and anxiety (RR: 3.61). ${ }^{28}$ Interestingly, the study of ten Have et $\mathrm{al}^{28}$ found no support that having a poor-quality job was associated with a better mental health compared to being unemployed or disabled.

The study of Snorradottir et a ${ }^{29}$ investigated psychological distress among surviving bank employees in Iceland who were entangled in a downsizing and restructuring process due to the financial crisis. The results of the study showed that being directly involved in organizational and structural change was associated to the development of psychological distress. Such restructuring factors as working in a downsized department, being transferred to another department, and undergoing salary reduction had, in particular, strong association with the psychological distress. Environment factors such as high job demand and low job control played a part in perceived psychological distress but only to a limited degree. ${ }^{29}$ The negative effects of the psychological distress could be partly attenuated by the empowering leadership and support from friends and family. ${ }^{29}$

Chang et $\mathrm{al}^{30}$ investigated the impact of the global economic crisis on international trends in suicides. The authors analyzed data on suicides from 54 countries (27 in Europe, 18 in America, eight in Asia, and one in Africa) derived from the World Health Organization mortality database and Centers for Disease Control online database. They completed a time trend analysis comparing the suicide rates in 2009 (during the crisis) with those during the period of 2000-2007 (before the crisis). Chang et $\mathrm{al}^{30}$ found that there were 4,884 more suicides in 2009 compared with the number of expected suicides (calculated basing on the previous trends). The increase in suicides mainly occurred among European and American men, the suicide rates $4.2 \%$ and $6.4 \%$ higher, respectively, than expected based on the previous trends. No significant excess in suicides was found among women. The 15-24 years age group showed a higher increase in suicide rates in the European countries (an increase of 11.7\%), and the 45-64 years age group demonstrated a higher increase among American countries (an increase of 5.2\%). Finally, Chang et $\mathrm{al}^{30}$ correlated some economic indicators, like gross domestic product (GDP) and unemployment rates, with the excess suicides. They found that the association between the 
increase in suicides and unemployment rates was particularly evident in countries where the unemployment rate before the crisis (2007) was relatively low $(<6.2 \%){ }^{30}$

Drydakis $^{31}$ investigated the negative effects of unemployment on self-reported (mental) health of the working population in Greece. The researcher used six annual waves of the Longitudinal Labor Market Study covering the period 2008-2013. The author found that unemployment resulted in a deterioration of both physical and mental health during the period 2008-2009 in comparison with the period 2010-2013. In the study by Drydakis, ${ }^{31}$ women were more negatively affected by unemployment in terms of their physical and mental health in comparison to men.

In 2011 in Greece, there was a 40\% reduction of hospital budgets leading to medical supply shortages. ${ }^{6}$ Hence, Rachiotis et $\mathrm{al}^{6}$ investigated the relationship between medical supply shortages and burnout in a population of 303 health care workers. Eighty-eight percent of respondents reported experiencing significant medical supply shortages. Moreover, $84 \%$ of the participants who experienced medical supply shortages reported that these shortages had a negative impact on the quality of health care provided to the patients.

The results showed that the prevalence of emotional exhaustion, depersonalization, and low personal accomplishment among health care workers were 44.5\%, 43.2\%, and $51.5 \%$, respectively. ${ }^{6}$ The risk factors for emotional exhaustion were the type of hospital (odds ratio [OR]: 3.88 in tertiary/universitary hospital), the type of work (nursing personnel and physicians had an increased risk, OR: 3.53), the medical supply shortages (OR: 2.92), and the absence of satisfactory rest after the night shifts (OR: 1.82). ${ }^{6}$ The same risk factors among health care workers in Greece were responsible for depersonalization and low personal accomplishment.

\section{Economic crisis and physical health}

Mattei et $\mathrm{al}^{32}$ investigated the impact of the crisis in Italy. They observed the changes over time (from the year 2000 to 2010) of several objective parameters, such as all-cause mortality, cardiovascular mortality, suicide, consumption of alcohol, consumption of antidepressants (ADs), traffic fatalities, rate of unemployment, and GDP. The results demonstrated that the rise of unemployment in Italy (which reached $8.4 \%$ in 2010) and the fall of GDP were not followed by an increase in all-cause mortality. However, the mortality due to cardiovascular causes increased. ${ }^{32}$ Some researchers explained that this could be due to the increase of workrelated stress that activates the pituitary-adrenal system with release of catecholamines that have a well-known role in cardiovascular events. ${ }^{41}$ Traffic fatalities and the consumption of alcohol decreased, but the finding in this case could be linked not to a consequence of economic crisis but rather to several successful prevention programs that the government established. $^{32}$ The number of suicides remained stable, but the percentage of the suicides attributable to reasons of an economic/financial nature increased (from $6.51 \%$ to $11.6 \%$ of all suicides in 2010). A final data analysis was linked to the use of selective serotonin reuptake inhibitor ADs and nonselective serotonin reuptake inhibitor ADs. The use of both types of drugs increased during crisis, even though the number of suicides, as mentioned, remained stable. ${ }^{32}$

Modrek and Cullen ${ }^{33}$ examined the situation of workers of Alcoa, a large aluminum manufacturer with several plants in the US. Due to the economic crisis, the organization had to make cuts in production resulting in layoffs. The authors grouped the Alcoa plants into different categories, based on the number of layoffs they had (ie, high layoff, mid layoff, and low layoff plants). ${ }^{33}$ The new incidences of four chronic conditions, ie, chronic obstructive pulmonary disease/asthma, hypertension, diabetes, and depression, were measured and linked to consequences of economic crisis. It has been found that people who worked in the high layoff plants were at a higher risk of developing hypertension (3.3\% of new cases, OR: 1.91); this was especially pronounced among the salaried workers (probably because the salaried workers of Alcoa had more job insecurity than the hourly workers who were better protected, according to corporate policy). The salaried workers in high layoff plants also had an increased risk of developing diabetes. ${ }^{33}$

Astell-Burt and Feng ${ }^{34}$ used a large social survey, administered every 3 months, from January-March 2006 to October-December 2010. The study aimed to assess the general health of the UK respondents and some particular health conditions such as depression, mental illness, cardiovascular diseases, and respiratory disorders. The results demonstrated that the self-perceived poor health status increased by $4.7 \%$ between early 2006 and late 2010 . This growth correlated with the rise in unemployment (up 2.5\%, from $4.5 \%$ to $7 \%$ ). An increased prevalence of all the health conditions mentioned previously was also identified, however only starting from April 2009. For the cardiovascular diseases, the increased prevalence rate was observed a little later (ie, October 2009). ${ }^{34}$ The development of mental illness and depression seems to also be related to the rate of unemployment (OR: 3.18 for the unemployed and 2.93 for the employed). 
Loerbroks et a ${ }^{35}$ investigated the link between the new cases of asthma and economic crisis in Germany. The authors hypothesized that the perceived job insecurity will be related to the incidents of asthma. In total, 105 new cases of asthma occurred during the period of 2009 and 2011. In the fully adjusted model, the risk of asthma increased by $24 \%$. High job insecurity, compared to none or low, was linked to roughly $60 \%$ excess risk of asthma.

Sedano de la Fuente et $\mathrm{al}^{36}$ investigated the change in the number of the incidences of occupational injuries before and after the onset of the economic crisis. The authors identified the year 2007 as a turning point (the year in which Spain began to feel the first effects of economic recession). Starting from the year 2007, the unemployment rate started to grow, while the number of workplace injuries and injury rate started to reduce. ${ }^{36}$ The authors showed that construction and industrial sectors demonstrated the greatest decrease in workplace accidents ( $>50 \%$ and $42 \%$ reduction, respectively). It was also demonstrated that the average age of injured workers increased (from 32.5 to 38.5 years). There was a rise in the number of injured workers with more work experience (injured workers had an average of 57.8 months of experience in 2009 versus an average of 35.2 months in 2005). Finally, there was a greater decrease in injuries among workers with temporary contracts. ${ }^{36}$

The Sigursteinsdòttir and Rafnsdottir ${ }^{37}$ study focused on sickness, and sickness absence in a population of municipality employees who remained at work after the economic crisis in Iceland. The proportion of employees who had never been absent due to sickness, dropped, both in downsized and nondownsized workplaces. ${ }^{37}$ In addition, there was an increase in the number of days employees remained off work due to sickness, both at downsized and non-downsized workplaces. Finally, the proportion of those who had gone to work while sick increased and was higher at the downsized workplaces.

\section{Discussion}

All the studies included in the present review demonstrated that the recent economic crisis was an important stressor that had negative effects on the health of workers and the general population. Most of the studies demonstrated an increased prevalence of mental health problems that coincided with the outbreak of the crisis. ${ }^{5,621-31}$ To investigate the relationship between mental health status and economic crisis, authors have used different parameters: Wang et al, ${ }^{21}$ Gili et al, ${ }^{23}$ Avcin et al, ${ }^{24}$ Sargent-Cox et al,,${ }^{25}$ Lee et al, ${ }^{5}$ and ten Have et $\mathrm{al}^{28}$ have used the new onset of depression, ${ }^{5,21,23-25}$ dysthymia, ${ }^{21,23,28}$ and anxiety. ${ }^{5,23-25,28}$ All of these studies demonstrated an increased prevalence of these clinical conditions together with the outbreak of the economic crisis and the rising rate of unemployment. ten Have et $\mathrm{al}^{28}$ identified low decision latitude, high psychological job demand, low job security, and low coworker support as factors linked to mental health problems.

Mattei et $\mathrm{al}^{32}$ used mortality, rate of suicide, and the use of ADs as parameters to measure individuals' mental and physical health. The researchers demonstrated an increase in the percentage of suicides attributed to the economic reasons. ${ }^{32}$ This was especially pronounced in entrepreneurs of northeast Italy who had large losses of money.

In addition to issues related to mental health, Modrek and Cullen, ${ }^{33}$ Astell-Burt and Feng, ${ }^{34}$ and Loerbroks et $\mathrm{al}^{35}$ investigated other health conditions. Modrek and Cullen ${ }^{33}$ used such health parameters as chronic diseases (hypertension, diabetes, asthma, as well as depression), while Loerbroks et $\mathrm{a}^{35}$ focused only on the correlation between asthma and recession. The results, which showed an increase in the prevalence of new cases of hypertension, diabetes, and asthma, can be explained by work-related stress, which can lead to hyperactivation of the pituitary-adrenal axis, with release of catecholamines that may have a negative effect on the cardiovascular system. ${ }^{32}$ The development of asthma may be similarly explained. As Loerbroks et al suggested, a chronic stress, like the work-related stress caused by the crisis, could alter the regulation of the sympathetic-adreno-medullary nervous system and the hypothalamic-pituitary-adrenal axis, which could then exert strong immunomodulatory effects and result in an atopy-biased response favoring allergic outcomes. ${ }^{35}$

Chan et $a l,{ }^{26}$ Chang et $a 1,{ }^{30}$ and Miret et $\mathrm{al}^{27}$ used the number of suicides as a parameter to assess the impact of the crisis. The results of the studies were divergent: Chan et $\mathrm{a}^{26}$ and Chang et $\mathrm{al}^{30}$ demonstrated an increased number of suicides during the period of economic crisis, whereas Miret et $\mathrm{al}^{27}$ demonstrated that the prevalence of suicide attempts and ideation had not increased significantly in 2011-2012 compared to 2001-2002.

Chan et $\mathrm{al}^{26}$ found that the risk of suicides was especially pronounced among managers and senior officials. The authors suggest that they found themselves facing a very difficult economic situation that probably led to the development of a huge amount of stress that favored the onset of mental illnesses and facilitated suicide ideation or attempts.

Chang et $a l^{30}$ demonstrated that the number of suicides was more increased in nations that had low levels of unemployment before the crisis. ${ }^{30}$ Such findings could probably also be explained by the fact that people in these nations 
faced a sudden worsening of economic and employment situation and this deterioration may have caused an increase in work-related stress, development of psychiatric disorders, and an increase in the number of suicides.

Sedano de la Fuente et $\mathrm{al}^{36}$ analyzed occupational injuries as a potential consequence of economic crisis. The demonstrated decrease in occupational injuries, particularly among young people, showed that they are probably the first ones to lose their jobs during the economic recession. ${ }^{36}$ It could be that the number of injuries decreases due to workers' fear of losing their jobs; that is, this motivates them to not report the minor injuries.

Although all the authors agreed on the negative impact of the economic crisis on health, not all agreed on the type of people most affected. Wang et $\mathrm{al}^{21}$ recognized that people with higher risk for depression and dysthymia are married or in a common-law relationship. Among these individuals, the fear of losing jobs, wages, and becoming unable to take care of the family can cause a high level of stress that affects mental health.

The findings presented by Lee et $\mathrm{al}^{5}$ were contradictory. The results demonstrated that a higher risk of developing MDD was seen in widowers and divorcees. It seems that among these individuals, stressful experiences are increased not only due to job insecurity but also due to the lack of social support.

Lee et $\mathrm{al}^{5}$ and Sargent-Cox et $\mathrm{al}^{25}$ agreed that adults older than 55 years have an increased risk for poorer (mental) health during the time of crisis. The explanation could be that these people who are close to retirement, experience stress due to the fear of losing their jobs and not being able to find a new one because of their older age.

Chang et $\mathrm{al}^{30}$ identified two age groups that had an increased risk for suicides in 2009. One was the 15-24 years age group in the European countries, and the other was the 45-64 years age group in the American countries. ${ }^{30}$

Gili et $\mathrm{al}^{23}$ and Astell-Burt and Feng ${ }^{34}$ in their studies identified that the unemployed, and those who have mortgage payment difficulties are at a higher risk for health problems. The unemployed experience high levels of stress due to the lack of occupation and low income. However, simultaneously, the employed also suffer the impact. In fact, with the increase of the unemployment rate, those who remain in jobs feel insecure and also experience health-related outcomes. ${ }^{34}$

Chang et $\mathrm{al}^{30}$ showed an increase in the number of suicides among men only, while, Drydakis ${ }^{31}$ demonstrated that women were more affected than men.

According to all authors, the economic crisis of 2008 has worsened the health of workers and the general population.
The main cause for this was work-related stress. The rise in layoffs and budget cuts brought survivors toward higher job insecurity, increased fear of becoming unemployed, and the consequent increase in stress. ${ }^{34}$ The work-related stress also increases due to reorganization of work, which brings increased workload, superior number of shifts, and hours of work. ${ }^{24}$ In addition, many workers suffered a reduction in wages ${ }^{5}$ resulting in the development of work dissatisfaction that can lead to burnout syndrome. ${ }^{6}$ The work-related stress, causing neuroendocrine dysregulations, may also explain an increase of pathological conditions such as hypertension and asthma. ${ }^{35}$

Finally, it is important to remember how the crisis affects not only people of working age. It is important to mention how families and, in particular children, may be indirectly affected by the economic crisis. Rajmil et $\mathrm{al}^{42}$ performed a systematic review with the purpose to investigate the impact of the 2008 economic crisis on children. Their review showed an increase in infant mortality in Greece during the period of financial crisis. The increase in food prices combined with the rise in unemployment and wage reductions has probably caused worsening nutrition habits and quality of life in disadvantaged families. Thus, worsening the economic and working situation of men and women could harm children's health as well.

The studies reviewed in the present paper have several limitations. First of all, most of the studies are cross-sectional, except for Sargent-Cox et al, ${ }^{25}$ Sigursteinsdòttir and Rafnsdottir, ${ }^{37}$ and Drydakis. ${ }^{31}$ Another limitation is that most of the studies did not use the objective parameters but rather the self-reports. However, the studies of Chan et al, ${ }^{26}$ Miret et al, ${ }^{27}$ Chang et al, ${ }^{30}$ and Sedano de la Fuente et $\mathrm{al}^{36}$ used objective parameters, such as the number of suicides, attempts at suicide, and the number of injuries.

Another important limitation is that we relied on only one database (PubMed database). In addition, we only included those studies in which the keywords appeared in the abstract or title.

Finally, only those studies that were published in the English language were included in the present review, hence limiting a great part of the knowledge about the potential impact of economic crisis on health.

\section{Conclusion}

It is evident that the financial crisis, which began in 2007-2008, had a negative impact on working conditions and health of people. Further studies are still needed to analyze the relationship between economic crisis, work-related stress, and health outcomes. In particular, it would be interesting 
to implement longitudinal studies that would identify the change in the prevalence of health problems together with the variation of economic and social conditions.

\section{Acknowledgment}

The authors are extremely grateful to Dr Milda Perminienè whose contribution was crucial to the realization of this paper.

\section{Disclosure}

The authors report no conflicts of interest in this work.

\section{References}

1. Acharya V, Philippon T, Richardson M, Roubini N. The financial crisis of 2007-2009: causes and remedies. Finan Markets Inst Instrum. 2009;18(2):89-137.

2. Goodman CJ, Mance SM. Employment loss and the 2007-09 recession: an overview. Mon Labor Rev. 2011;134(4):3-12.

3. Lapavitsas C, Kaltenbrunner A, Lindo D, et al. Eurozone crisis: beggar thyself and thy neighbour. J Balkan Near E Stud. 2010;12(4):321-373.

4. European Foundation for the Improvement of Living and Working Conditions. Impact of the crisis on working conditions in Europe. 2014.

5. Lee S, Guo WJ, Tsang A, et al. Evidence for the 2008 economic crisis exacerbating depression in Hong Kong. J Affect Disord. 2010;126: 125-133.

6. Rachiotis G, Kourousis C, Kamilaraki M, Symvoulakis EK, Dounias G, Hadjichristodoulou C. Medical supplies shortages and burnout among Greek health care workers during economic crisis: a pilot study. Int J Med Sci. 2014;11:442-447.

7. Giorgi G, Arcangeli G, Mucci N, Cupelli V. Economic stress in workplace: the impact of fear the crisis on mental health. Work. 2015;51(1): 135-142. doi:10.3233/WOR-141844.

8. Mucci N, Giorgi G, Cupelli V, et al. Work-related stress assessment in a population of Italian workers. The Stress Questionnaire. Sci Total Environ. 2015;502:673-679.

9. Mucci N, Giorgi G, Fiz Perez J, Iavicoli I, Arcangeli G. Predictors of trauma in bank employee robbery victims. Neuropsychiatr Dis Treat. 2015;2015(11):2605-2612.

10. Mucci N, Giorgi G, Cupelli V, Arcangeli G. Future health care workers mental health problems and correlates. World Appl Sci J. 2014;30(6): $710-715$.

11. Giorgi G, Leon-Perez JM, Cupelli V, Mucci N, Arcangeli G. Do I just look stressed or am I stressed? Work-related stress in a sample of Italian employees. Ind Health. 2014;52(1):43-53.

12. Giorgi G, Shoss MK, Leon-Perez JM. Going beyond workplace stressors: economic crisis and perceived employability in relation to psychological distress and job dissatisfaction. Int J Stress Manag. 2015;22(2):137-158.

13. Houdmont J, Kerr R, Addley K. Psychosocial factors and economic recession: the Stormont study. Occup Med (Lond). 2012;62(2):98-104.

14. Stroup DF, Berlin JA, Morton SC, et al. Meta-analysis of observational studies in epidemiology: a proposal for reporting. JAMA. 2000;283:2008-2012.

15. World Bank. World development indicators. 2011.

16. Weisbot M, Montecino J; Center for Economic and Policy Research. Alternatives to fiscal austerity in Spain. 2010.

17. Business Cycle Dating Committee of the National Bureau of Economic Research. Determination of the December 2007 peak in economic activity. 2008 .

18. Alvarez JA. La banca espanola ante la actual crisis financiera. Estabilidad Financiera. 2008;15:21-38.

19. Podsakoff, PM, MacKenzie SB, Lee JY, Podsakoff NP. Common method biases in behavioral research: a critical review of the literature and recommended remedies. J Appl Psychol. 2003;88:879-903. doi:10.1037/0021-9010.88.5.879.
20. Zapf D, Dormann C, Frese M. Longitudinal studies in organizational stress research: a review of the literature with reference to methodological issues. J Occup Health Psychol. 1996;1(2):145-169.

21. Wang JL, Smailes E, Sareen J, Fick GH, Schmitz N, Patten SB. The prevalence of mental disorders in the working population over the period of global economic crisis. Can Child Adolesc Psychiatr Rev. 2010;55(9): 598-605.

22. Evans-Lacko S, Knapp M, McCrone P, Thornicroft G, Mojtabai R. The mental health consequences of the recession: economic hardship and employment of people with mental health problems in 27 European countries. PLoS One. 2013;8(7):e69792.

23. Gili M, Roca M, Basu S, McKee M, Stuckler D. The mental health risks of economic crisis in Spain: evidence from primary care centres, 2006 and 2010. Eur J Public Health. 2012;23(1):103-108.

24. Avcin BA, Kucina AU, Sarotar BN, Radovanovic M, Plesnicar K. The present global financial and economic crisis poses an additional risk factor for mental health problems on the employees. Psychiatr Danub. 2011;23 Suppl 1:S142-S148.

25. Sargent-Cox K, Butterworth P, Anstey KJ. The global financial crisis and psychological health in a sample of Australian older adults: a longitudinal study. Soc Sci Med. 2011;73:1105-1112.

26. Chan CH, Caine ED, You S, Fu KW, Chang SS, Yip PSF. Suicide rates among working-age adults in South Korea before and after the 2008 economic crisis. J Epidemiol Community Health. 2014;68:246-252.

27. Miret M, Caballero FF, Huerta-Ramirez R, et al. Factors associated with suicidal ideation and attempts in Spain for different age groups. Prevalence before and after the onset of the economic crisis. J Affect Disord. 2014;163:1-9.

28. ten Have M, van Dorsselaer S, de Graaf R. The association between type and number of adverse working conditions and mental health during a time of economic crisis (2010-2012). Soc Psychiatry Psychiatr Epidemiol. 2015;50(6):899-907. doi:10.1007/s.00127-015-1009-2.

29. Snorradottir A, Vilhjàlmsson R, Rafnsdottir GL, Tomasson K. Financial crisis and collapsed banks: psychological distress and work related factors among surviving employees - a nation-wide study. Am J Ind Med. 2013;56:1095-1106.

30. Chang SS, Stuckler D, Yip P, Gunnell D. Impact of the 2008 global economic crisis on suicide: time trend study in 54 countries. BMJ. 2013; 347:f5239. doi:10.1136/bmj.f5239.

31. Drydakis N. The effect of unemployment on self-reported health and mental health in Greece from 2008 to 2013: a longitudinal study before and during the financial crisis. Soc Sci Med. 2015;128:43-51.

32. Mattei G, Ferrari S, Pingani L, Rigatelli M. Short-term effects of the 2008 Great Recession on the health of the Italian population: an ecological study. Soc Psychiatry Psychiatr Epidemiol. 2014;49: 851-858.

33. Modrek S, Cullen MR. Health consequences of the 'Great Recession' on the employed: evidence from an industrial cohort in aluminum manufacturing. Soc Sci Med. 2013;92:105-113.

34. Astell-Burt T, Feng X. Health and the 2008 economic recession: evidence from the United Kingdom. PLoS One. 2013;8(2):e56674.

35. Loerbroks A, Bosch JA, Douwes J, Angerer P, Li J. Job insecurity is associated with adult asthma in Germany during Europe's recent economic crisis: a prospective cohort study. J Epidemiol Community Health. 2014;68:1196-1199.

36. Sedano de la Fuente V, Camino Lopez MA, Fontaneda Gonzalez I, Gonzalez Alcantara OJ, Ritzel DO. The impact of the economic crisis on occupational injuries. J Safety Res. 2014;48:77-85.

37. Sigursteinsdòttir H, Rafnsdottir GL. Sickness and sickness absence of remaining employees in a time of economic crisis: a study among employees of municipalities in Iceland. Soc Sci Med. 2015;132: 95-102.

38. Greenwood DC, Muir KR, Packham CJ, Madeley RJ. Coronary heart disease: a review of the role of psychosocial stress and social support. J Public Health Med. 1996;18:221-231.

39. Tennant C. Work-related stress and depressive disorders. J Psychosom Res. 2001;51(5):697-704. 
40. Brown C, Davis K. Australia's experience in the global financial crisis. In: RW Kolb, editor. Lessons from the Financial Crisis: Causes, Consequences and Our Economic Future. John Wiley and Sons, Hoboken, NJ; 2010:537-544.

41. Australian Bureau of Statistics (2006-2010). Labour force, Australia cat. 6202.0. 2006-2010.
42. Rajmil L, Fernandez de Sanmamed JM, Choonara I, et al; International Network for Research in Inequalities in Child Health (INRICH). Impact of the 2008 economic and financial crisis on child health: a systematic review. Int J Environ Res Public Health. 2014;11(6):6528-6546.

\section{Publish your work in this journal}

Neuropsychiatric Disease and Treatment is an international, peerreviewed journal of clinical therapeutics and pharmacology focusing on concise rapid reporting of clinical or pre-clinical studies on a range of neuropsychiatric and neurological disorders. This journal is indexed on PubMed Central, the 'PsycINFO' database and CAS, and is the official journal of The International Neuropsychiatric Association (INA). The manuscript management system is completely online and includes a very quick and fair peer-review system, which is all easy to use. Visit http://www.dovepress.com/testimonials.php to read real quotes from published authors.

Submit your manuscript here: http://www.dovepress.com/neuropsychiatric-disease-and-treatment-journal 